\title{
Efficacy of composite perichondrial-chondral graft in type 1 tympanoplasty a comparative study
}

\author{
Vijayasundaram S. ${ }^{1}$, Satyaprabhakara Rao Y. ${ }^{2}$, Deepthi Y. ${ }^{3}$ \\ ${ }^{1}$ Dr. Vijayasundaram Sundararajan, Associate Professor, ${ }^{2}$ Dr. Satyaprabhakara Rao, Professor and Head of the \\ Department, ${ }^{3}$ Dr. Deepthi Y., Junior Resident; all authors are attached with Department of Otorhinolaryngology Head \\ and Neck Surgery, NRI Medical College, Guntur, Andhra Pradesh, India.
}

Correspondence Author: Dr. Vijayasundaram S., Associate Professor,Department of Otorhinolaryngology Head and Neck Surgery, NRI Medical College, Guntur, Andhra Pradesh. E-mail: dr.vijayasundaram@gmail.com

\begin{abstract}
Introduction: Temporalis fascia is the most commonly used material for tympanic membrane reconstruction, followed by perichondrial graft. Objective: To compare the efficacy of cartilage graft versus temporalis fascia graft. Study Design is Randomised prospective study in ENT department of tertiary care hospital (NRI medical college and general hospital) Material and Methods: A sample size of 60 patients used, who were randomly divided into two groups - Group A (Perichondrial-chondral graft) and Group B (Temporalis fascia graft). They were subjected to a detailed history and clinical examination. After surgery, they were followed-up at one month, three months, and six months to check for graft uptake and hearing assessment byPure Tone Audiometry. Results: It was observed that in Group A 100\% (30) of the patients achieved complete closure of tympanic membrane by the end of the first month, and it remained unchanged till the end of 6 months. In Group B, 96.6\% (29) patients achieved complete closure by the end of the 1st month, and it reduced to $93.3 \%$ (28) at the end of six months.Conclusions: Although there is no statistical difference in graft uptake and hearing improvement between the groups, the graft uptake and hearing results for perichondrial-chondral graft in comparison with temporalis fascia grafts are slightly better.
\end{abstract}

Keywords: Tympanoplasty, Temporalis fascia, Perichondrial graft.

\section{Introduction}

The treatment of chronic otitis media focuses on the mucosal infection in the tympano-mastoid compartment. When a chronic discharging ear cannot be cured by conservative treatment and have ruled out tubal discharge resulting from nasopharyngeal or sinus suppuration of from allergies, reconstructive middle ear surgery is indicated [1] Since the introduction of the concepts of tympanoplasty by Wullstein [2], Zollner [3] and others in 1953, surgery for inflammation of the middle ear has undergone a revolution.

Type I tympanoplasty through a post-aural approach with temporalis fascia is a commonly done procedure. Surgeons, though, based on their preference, employ various techniques like underlay, overlay, or inlay methods. Different materials are also used to ensure the adherence of the graft with the remnant tympanic membrane. Wullstein and Zollner used split-skin grafts

\footnotetext{
Manuscript received: $14^{\text {th }}$ June 2019

Reviewed: $24^{\text {th }}$ June 2019

Author Corrected: $30^{\text {th }}$ June 2019

Accepted for Publication: $3^{\text {rd }}$ July 2019
}

in 1953 [2,3], Shea used vein grafts in 1960 [4]. Heerman used fascia grafts in 1960 [5], Jansen (1963) and Goodhill (1967) used perichondrium [6]. Such abundance of material implies that there is no clear cut favourite and the choice is based on surgeon preference[7,8].

Temporalis fascia remains the most commonly used material for tympanic membrane reconstruction, with a success rate of $93-97 \%$ in primary tympanoplasties [9]. The next regularly used one is perichondrial graft [10]. The main advantages of temporalis fascia graft are

1. It can be obtained through the same post aural incision, which we commonly employ for tympanoplasties and also is available in sufficient quantity.

2. The basal metabolic rate of the tympanic membrane is almost equal to that of temporalis fascia.

3. The thickness of fascia is similar to that of the tympanic membrane. 


\section{Original Research Article}

The various techniques of cartilage tympanoplasty include perichondrium/cartilage island flap, cartilage shield techniques, palisade technique, and inlay butterfly graft technique [5]. The different cartilages used are tragal, conchal, triangular fossa, and septal cartilage.

The main advantages of using the perichondrialchondral graft are:

1. It has a low basal metabolic rate.

2.It receives its nutrients by diffusion, so minimal chances of graft failure.

3.It contributes minimally to an inflammatory tissue reaction.

4. It is well incorporated with the layers of the tympanic membrane.

5. It also provides firm support to prevent retraction and can resist deformation from pressure variation [10].

A comparative study of different graft material (temporalis fascia graft, tragal perichondrial graft, areolar tissue graft) used in myringoplasty to identify the ideal graft was done bySingh BJ et al [11].

Another comparative study was done by Bhoopendra S et al [12] where they compared temporalis fascia,tragal perichondrium, vein graft and fascia lata graft uptake in Tympnaoplsty.

The lack of consensus regarding the best graft material, due to the abundance of materials used and the challenge surgeons face in achieving consistent good results hasmotivated us to undertake this comparative study. In the last few years cartilage grafts gained more popularity in the reconstruction of middle ear ossicles and eardrum, hence this study is designed to evaluate and compare the graft uptake and audiological outcomes of patients undergoing type 1 tympanoplasty using perichondrial-chondral graft versus patients undergoing the same surgery using temporalis fascia graft.

\section{Materials and Methods}

Study design: Randomized prospective study.

Setting: ENT Department of a tertiary care hospital (NRI Medical College and General Hospital, Chnnakakani)

Study period: March 2016-2018.

Sample size: 60 patients
Sampling methods: The procedure A and procedure B were performed alternatively.

Sampling size calculation: A sample of 60 patients were obtained and some patients were lost to follow up .

Data analysis: Med Calc's software was used to perform all statistics, Fischer exact test was used to compare clinical significance of graft uptake between 2 groups at 1 month and 6 months. A paired T-test was done to know the clinical significance of preop PTA and post-op PTA at 1,3,6 months in the group A and B.

Independent T-test was used to test the clinical significance of PTA results between group A and group $\mathrm{B}$ at 1 month, three months, six months.

This study was approved by the institutional ethics committee at NRI hospital and medical college.

\section{Inclusion Criteria}

1. All patients planned for Type 1 Tympanoplasty from March 2016 to March 2018

2. Patients with chronic otitis media - mucosal type

3. A dry ear for at least four weeks

4. Ossicular integrity intact

5. Age: 18 to 60

\section{Exclusion criteria}

1. Patients under the age of 18 and over the age of 60

2. Ossicular integrity not maintained

3. Patients with active com

4. Patients with SNHL and Mixed Hearing Loss

5. COM-Squamosal

6. Revision cases

7. COM with complications

Methodology- The patients selected as per the inclusion and exclusion criteria were subjected to a detailed history and clinical examination.

The following points were noted in history taking:

- Type of ear discharge and duration

- Last episode of ear discharge

- Presence of hearing loss

- Ear pain

- Tinnitus or Vertigo

- Presence of Nasal complaints (nasal block, mouth breathing) 


\section{Original Research Article}

\section{In examination the following were done:}

- Oto-microscopy to view the site and size of the perforation.

- To assess if the ear is dry (inactive).

- To evaluate the middle ear mucosa

- Anterior and posterior rhinoscopy to rule out sinusitis and nasopharyngeal pathologies

- Tuning fork tests to assess the hearing loss

Patients were counselled from the time of diagnosis till the last follow up with the help of brief audiovisuals and were explained in a simple language

\section{Investigations}

- Complete blood count

- Coagulation profile

- Pure tone audiogram

Anaesthesia- Patients were operated under general anaesthesia.

Infiltration- 2\% lignocaine with 1:100000 adrenaline was used in the dose of not exceeding $7 \mathrm{mg} / \mathrm{kg}$ body weight

Preoperative Preparation- Patients were admitted one day before surgery, Xylocaine sensitivity was done, and preoperative antibiotic were given, overnight fasting assured.

\section{Surgical technique}

\section{Group-A (Perichondral-Chondral Graft)}

Harvesting of tragal cartilage: $15 \mathrm{~mm}$ long incision made $2-3 \mathrm{~mm}$ below the dome of tragal cartilage in one sweep through the skin, posterior perichondrium, cartilage, and anterior perichondrium. The extraperichondrialplane was created on both sides, and the cartilage graft was excised in size of $15 \times 10 \mathrm{~mm}$ with perichondrium intact on both sides.

Shaping of composite cartilage-perichondrium island graft- After removing the perichondrium from the convex side of the graft, a round disk of a diameter of $9-10 \mathrm{~mm}$ was marked. The disk was shaped in the anterior part of the graft, allowing a $1 \mathrm{~mm}$ long anterior and $5 \mathrm{~mm}$ long posterior perichondrial flap. The superfluous cartilage $2-3 \mathrm{~mm}$ in width was removed from the centre of the round disk.

The microscope was focussed and fixed, the margin of remnants of the tympanic membrane was freshened, and the under-surface of tympanic membrane cleared, the tympano-meatal flap was elevated \& handle of malleus bared. Ossicular chain integrity and mobility were assessed.

Middle ear was packed with gel foam. The graft was placed medial to handle of malleus by underlay technique. Middle ear was packed with medicated gel foam, and the flap was reposited back. The canal was packed with medicated gel foam and umbilical tape. The wound was sutured in two layers, and a mastoid dressing was done.

Group-B (Temporalis Fascia Graft Tympanoplasty)Patient's ear was cleaned using savlon, spirit, and povidone-iodine in that order and draped, ensuring complete asepsis. The ear was inspected using Gruber's ear speculum, and type of approach was decided. Local anaesthetic (Xylocaine 2\% with 1:100000 Adrenaline) was infiltrated in the post-auricular and supra-auricular area and cartilaginous and bony canal.

Temporalis fascia graft harvested and meatotomy followed. The microscope was focussed and fixed, the margin of remnants tympanic membrane were freshened, and the under-surface of tympanic membrane cleared.

Tympano-meatal flap was elevated \& handle of malleus bared. Ossicular chain integrity and mobility were assessed. The graft was placed medial to handle of malleus by underlay technique. Middle ear was packed with medicated gel foam, and the flap was reposited back. The canal was packed with medicated gel foam and umbilical tape. Wound sutured in two layers, and the mastoid dressing was done.

Follow-up:At one month, three months, and six months

- Pure Tone Audiometry

- To check for graft up-take

\section{Results}

A total of 60 patients were included in the study, with 30 patients in each group. They were divided into two groups as Group A (Cartilage tympanoplasty) and Group B (Temporalis fascia graft tympanoplasty). 
Original Research Article

Table No1: Graft uptake - 1 Month POST OP

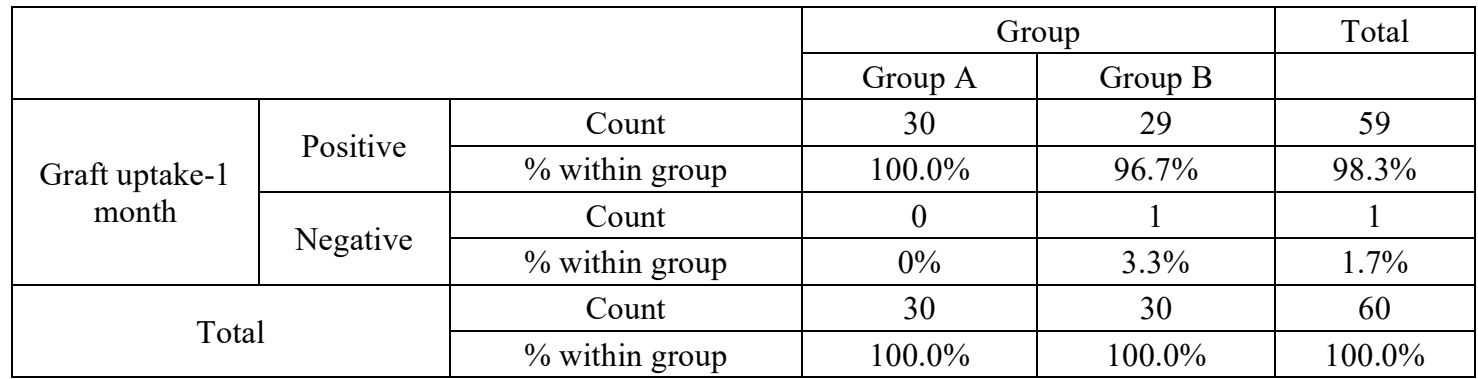

$P$ value 0.3135

In the first month, 30 patients from group A had positive graft uptake compared to 29 from group B. Only one patient from group B had a negative graft uptake while there were none from group A. (Table No.1). Fischer exact test was used to compare clinical significance between 2 groups, and the $\mathrm{P}$ value is 0.313 (no significance). Hence there is no significant difference in graft uptake in the first month between group A and B.

\section{Table No2: Graft uptake-6 Months POST OP}

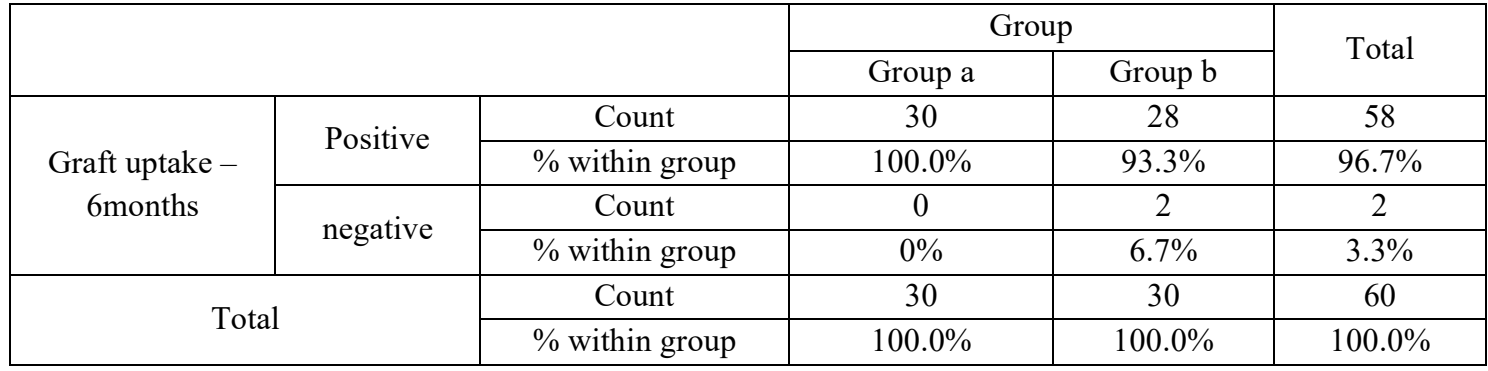

After six months, 30 patients from group A had positive graft uptake compared to 28 from group B. Only two patients from group B had a negative graft uptake while there were none from group A. Fischer exact test was used to compare clinical significance between 2 groups, and the $\mathrm{P}$ value is 0.1504 , so there is no statistical significance. Hence there is no significant difference in graft uptake after six months between group A and group B(Table No.2)

Table No.-3: Paired sample test of preop and postop PTA withingroup A and group B

\begin{tabular}{|c|c|c|c|c|c|c|c|c|}
\hline & \multicolumn{4}{|c|}{ Paired differences } & \multirow[t]{3}{*}{$\mathrm{T}$} & \multirow[t]{3}{*}{$\mathrm{DF}$} & \multirow{3}{*}{$\begin{array}{l}\text { Sig. (2- } \\
\text { tailed) }\end{array}$} \\
\hline & & \multicolumn{4}{|c|}{$95 \%$ Confidence interval of the difference } & & & \\
\hline & & Mean & $\begin{array}{c}\text { Std. Error } \\
\text { of } \\
\text { difference }\end{array}$ & Lower & Upper & & & \\
\hline Pair1 & $\begin{array}{l}\text { Pre OP PTA-Post OP } \\
\text { PTA-1 month group A }\end{array}$ & 8.97 & 0.598 & 7.74 & 10.19 & 14.99 & 29 & 0.0001 \\
\hline Pair 2 & $\begin{array}{l}\text { Pre OP PTA-POST OP } \\
\text { PTA-3 months group A }\end{array}$ & 10.37 & 0.718 & 8.90 & 11.84 & 14.43 & 29 & 0.0001 \\
\hline Pair 3 & $\begin{array}{l}\text { Pre OP PTA-POST OP } \\
\text { PTA-6months group A }\end{array}$ & 11.27 & 0.717 & 9.80 & 12.73 & 15.70 & 29 & 0.0001 \\
\hline Pair 4 & $\begin{array}{l}\text { Pre OP PTA-POST OP } \\
\text { PTA-1 month Group B }\end{array}$ & 8.57 & 0.550 & 7.44 & 9.69 & 15.57 & 29 & 0.0001 \\
\hline Pair 5 & $\begin{array}{c}\text { Pre OP PTA-Post OP } \\
\text { PTA-3months Group B }\end{array}$ & 10.10 & 0.596 & 8.88 & 11.32 & 16.95 & 29 & 0.0001 \\
\hline Pair 6 & $\begin{array}{c}\text { Pre OP PTA-post OP } \\
\text { PTA } 6 \text { months Group B }\end{array}$ & 10.70 & 0.672 & 9.33 & 12.07 & 15.93 & 29 & 0.0001 \\
\hline
\end{tabular}

PTA=Pure Tone Audiometry 
A paired T-test was done to know the clinical significance of preop PTA and post-op PTA at 1,3,6 months in the group A and $\mathrm{B}$ (table 3 ).

There is significant difference in pre-op and post-op pure tone audiogram for 1,3,6 months in both groups.(p value $=0.0001$ ) After 6 months of surgery the average hearing improvement in cartilage group was $11.26 \mathrm{dBHL}$ and $10.70 \mathrm{dBHL}$ in temporalis fascia group. $(\mathrm{p}>0.05)$

Independent T-test was used to test the clinical significance of PTA results between group A and group B at 1month, three months, six months.

Table No-4: Independent T-test of preop and post op PTA between Group A and Group B.

\begin{tabular}{|c|c|c|c|c|c|c|c|}
\hline & & & \multicolumn{2}{|c|}{$\begin{array}{l}95 \% \text { Confidence } \\
\text { Interval of the } \\
\text { Difference }\end{array}$} & \multirow[t]{2}{*}{$\mathrm{T}$} & \multirow[t]{2}{*}{$\mathrm{DF}$} & \multirow[t]{2}{*}{$\begin{array}{l}\text { Sig. (2. } \\
\text { tailed) }\end{array}$} \\
\hline & Mean & $\begin{array}{c}\text { Std. } \\
\text { Deviation }\end{array}$ & Lower & Upper & & & \\
\hline $\begin{array}{c}\text { Pre OP PTA } \\
\text { Group A, } \\
\text { Group B }\end{array}$ & $\begin{array}{l}36.73 \\
37.10\end{array}$ & $\begin{array}{l}3.19 \\
4.06\end{array}$ & -2.25 & 1.51 & $\begin{array}{c}- \\
0.392\end{array}$ & 58 & 0.696 \\
\hline $\begin{array}{c}\text { Post OP PTA -1 Month } \\
\text { Group A, } \\
\text { Group B }\end{array}$ & $\begin{array}{l}27.77 \\
28.37\end{array}$ & $\begin{array}{l}2.25 \\
2.40\end{array}$ & -0.53 & 1.87 & 1.116 & 58 & 0.269 \\
\hline $\begin{array}{c}\text { Post OP PTA - } 3 \text { Months } \\
\text { Group A, } \\
\text { Group B }\end{array}$ & $\begin{array}{l}26.37 \\
26.83\end{array}$ & $\begin{array}{l}2.22 \\
2.12\end{array}$ & -0.66 & 1.58 & 0.821 & 58 & 0.415 \\
\hline $\begin{array}{c}\text { Post OP PTA-6 months } \\
\text { Group A, } \\
\text { Group B }\end{array}$ & $\begin{array}{l}25.47 \\
26.40\end{array}$ & $\begin{array}{l}1.81 \\
2.04\end{array}$ & 0.06 & 1.92 & 1.868 & 58 & 0.066 \\
\hline
\end{tabular}

In this study $\mathrm{p}<0.05$ was considered as the level of significance.

All calculations were done using Med Calc's software.

\section{Discussion}

Type 1 Tympanoplasty is an age-old procedure done to treat chronic otitis media - mucosal disease by reconstructing the tympanic membrane. Various methods and materials have been used to improve the graft uptake and hearing of the patient. Improvement in hearing is essential as it is the primary complaint of most patients with chronic otitis media (mucosal). This study was conducted in the Department of Otorhinolaryngology, NRI Medical College and General Hospital.

Patients were selected from the outpatient department and randomly distributed into two groups. A sample size of 60 patients diagnosed as Chronic Otitis MediaMucosal type who satisfied the inclusion criteria. Patients were effectively counselled from the time of diagnosis till the last followup with the help of brief audio-visuals. explained and instructed in a simple language. Special emphasis was given on proper patient counselling as we felt the successrateoftympanoplasty was greatly influenced by patient's knowledgeof the disease and proper post operative care with consistent follow up. The mean age of the patients in this study was 32.87 years in cartilage group, and 33.23 years in temporalis fascia group with the minimum being 18 years and the maximum being 60 years. Patients in both groups were comparable in age wise and did not differ statistically.

In the present study, there were 14 males (46.7\%) and 16 females $(53.3 \%)$ in the cartilage tympanoplasty group. In temporalis fascia group there were 20 males $(66.7 \%)$ and ten females $(33.3 \%)$. However both the groups did not differ statistically from each other Diseased ear: In the cartilage group, out of 30 patients $3.3 \%$ (1) had bilateral ear disease, 56.7\% (17) had a disease in the right ear, and $40 \%$ (12) had a disease in the left ear.In temporalis fascia group, out of 30 
patients, $0 \%$ (0) had bilateral ear disease, 46.7\% (14) had a disease in the right ear and 53.3\% (16) in the left ear. Both of these groups were comparable and did not differ statistically.

Type of cartilage graft:Out of 30 patients, tragal cartilage was used in $100 \%$ (30) patients.

Type of cartilage technique: Out of 30 patients, $80 \%$ (24) of patients underwent cartilage tympanoplasty while $20 \%$ (6) underwent island graft tympanoplasty.

Graft uptake:Graft take-up rate was assessed by the complete closure of tympanic membrane perforations at the end of 1st, 3rd and 6th post-operative months, respectively. In the cartilage group, a full closure of tympanic membrane perforation was achieved in $100 \%$ (30) of patients at the end of the 1 st month.

This remained unchanged until the end of the 6th month. In temporalis fascia group, complete closure of tympanic membrane perforation was achieved in $96.6 \%$ (29) of patients and incomplete closure in 3.3\% (1) of patients at the end of the 1st month. The same results were obtained at the end of the 3rd month. By the end of 6 months, complete closure was achieved in 93.3\% (28) and 6.6\% (2) patients had incomplete closure.

Thus the graft uptake rate in cartilage graft was $100 \%$, and in temporalis fascia, it was $93.3 \%$. However, statistically, cartilage graft was not better than temporalis fascia.

The results were compared with the other studies and discussed as follows.

In comparison of Perichondrial graft uptake Nitin $\mathrm{p}$ et al [13] study showed $93.75 \%$ successful uptake with tragal perichondrium, Al Lackany et al [14] 92\%, Sprem N et al [15] 92\%,Singh et al[16] 90\%, Gupta et al [16] 91\% , Patil et al [17] 87.5\% and Dabhorkar et al[18] achieved $80 \%$. The present study showed $100 \%$ uptake of cartilage graft.

A comparative study conducted by Avani Jain et al [19] between island cartilage graft vs temporalis fascia graft in type 1 tympanoplasty showed a graft uptake rate of $97.1 \%$ for island cartilage graft which is close to our graft uptake rate of $100 \%$.

The present literature search has not revealed a study with a cartilage graft uptake of $100 \%$ as seen in the present study. Our literature search has not revelaed a cartilage graft uptake of $100 \%$ in perichondrial graft as seen in the present study. In comparison of Temporalis fascia graft uptake with other studies Lackany et al[14] showed a graft uptake of $80 \%$, Dabhorkar et al [18] $84 \%$, Patil et al[17] $86.67 \%$, Nitin p et al[13] $90 \%$ and Sprem N et al[15] $91 \%$ of successful temporalis fascia graft uptake which showed a lower value when compared to the present study where the graft uptake was $93.3 \%$. On the contrary Harman and tang[20] showed $95.3 \%$ of temporalis fascia graft, Mathai et al [21] 95\%, Singh et al [11] 95\% which showed higher value when compared to the present study of $93.3 \%$ successful temporalis fascia graft uptake.

A study conducted by Arvinder Singh et al [22] revealed a graft uptake which was better with tragal cartilage (95\%), and temporalis fascia graft $(90 \%)$ at 2 months post op, It came down to $(75 \%)$ in temporalis fascia and $(70 \%)$ in tragal cartilage group at the end of 6 months.

Audiological outcomes- There is a significant difference in pre-op and post-op pure tone audiogram for the 1st, 3rd, and 6th months in both groups. After six months of surgery, the average hearing improvement in cartilage group was $11.26 \mathrm{dBHL}$ and $10.70 \mathrm{dBHL}$ in the temporalis fascia group.

In comparison with other studies,Patil K et al study [17] revealed better hearing improvement with a mean gain of $10.92 \mathrm{db}$ in cartilage group and $9.36 \mathrm{db}$ in temporalis fascia group similar to the present study

A study by Arvinder Singh et al [22] revealed, hearing improvement was better with tragal cartilage with no statistical significance between the two groups.

Another similar comparative study byTarik Sapci et al[23], M.T. Kalcioglu et al [24],showed improvement in hearing levels with no statistical significance between the two groups.

Contrary to the present study Singh et al [11] noticed better hearing results with an average hearing improvement of $9.3 \mathrm{db}$ for Temporalis fascia graft as opposed to $8.5 \mathrm{db}$ for perichondrial graft.

In this study, authors effectively incorporated the techniquesinasample of 60 patients from aperiod of 2016-2018 at a tertiary hospital (NRI Medical college and hospital), and showed a success rate of (100\% graft uptake) perichondrial cartilage over temporal is fascia graft. It can be attributed to the effective counselling in the form of brief Audiovisuals as we believe the surgical outcome, which also dependson the patient 


\section{Original Research Article}

compliance and post op care is often overlooked. In the present literature search wehavenotfounda success rate of $100 \%$ perichondrial graft uptake as in the present study.

Limitations: The present study has some limitations. The limited sample size of the study could have affected the interpretation of the obtained result.

\section{Conclusion}

- Perichondrial chondral graft material for tympanoplasty is an excellent alternative to temporalis fascia.

- Although there is no statistical difference in both the groups, the hearing results for perichondrial-chondral graft $(11.26 \mathrm{dBHL})$ in comparison with temporalis fascia grafts $(10.70 \mathrm{dBHL})$ are slightly better.

- The perichondrial-chondral graft is found to be the superior autograft (100\% graft uptake) compared with temporalis fascia (93.3\%graft uptake), not only because of better graft integration rate but also due to slightly better hearing outcomes, as per findings in this study.

- However, further studies with larger sample size and multicentric data would help authenticate the observations in this context

\section{Author's contribution}

Dr.S. Vijaya Sundaram: Surgical technique incurporation, Data collection, manuscript preparation.

Dr. Y. Satya Prabhakara Rao: Surgical technique incorporation, Data collection, manuscript correction.

Dr. Deepthi Y: Assisted surgeries, Data collection, Review of literature, statistical analysis, manuscript preparation.

\section{Funding: Nil, Conflict of interest: Nil \\ Permission from IRB: Yes}

Acknowledgments: Authors would like to acknowledge Audiologist and statistician for their inputs and support throughout the study.

\section{References}

1. Proctor B. A statistical review of 177 tympanoplasties performed in 1957-1958. AMA Arch Otolaryngol. 1960;71(3):469-77.

2. Wullstein H. Theory and practice of tympanoplasty. Laryngoscope. 1956;66(8):1076-93. DOI:10.1288/000 05537-195608000-00008
3. Zollner F. The principles of plastic surgery of the sound-conducting apparatus. J Laryngol Otol. 1955; 69 (10):637-52.

4. SHEA JJ Jr. Vein graft closure of eardrum perforations. J Laryngol Otol. 1960;74:358-62. DOI:10. $1017 /$ s002221510005670x

5. Heermann J Jr, Heermann H, Kopstein E. Fascia and cartilage palisade tympanoplasty. Nine years' experience. Arch Otolaryngol. 1970;91(3):228-41.

6. Goodhill V. Tragal perichondrium and cartilage in tympanoplasty. Arch Otolaryngol. 1967;85(5):480-91.

7. Gibb AG, Chang SK. Myringoplasty (A review of 365 operations). J Laryngol Otol. 1982;96(10):915-30. DOI:10.1017/s0022215100093270

8. Dabholkar JP, Vora K, Sikdar A. Comparative study of underlay tympanoplasty with temporalis fascia and tragal perichondrium. Indian J Otolaryngol Head Neck Surg.2007;59(2):116-9.DOI:10.1007/s12070-0070035-0

9. Sheehy JL, Anderson RG. Myringoplasty. A review of 472 cases. Ann OtolRhinolLaryngol. 1980;89(4 Pt 1):331-4. DOI:10.1177/000348948008900407

10. Titoria $\mathrm{P}$, Alderson D. A technique for raising tragal perichondrium. Clin Otolaryngol. 2010;35(1):75. DOI: 10.1111/j.1749-4486.2009.02064.x.

11. Singh BJ, Sengupta A, Das SK, Ghosh D, Basak B. A comparative study of different graft materials used in myringoplasty. Indian J Otolaryngol Head Neck Surg. 2009; 61(2): 131-4. DOI: 10.1007/s12070-0090051-3. Epub 2009 Jun 14.

12. Singh B, Baka N, Kumar N, Purohit JP.Study of various grafts in closure of tympanic membrane perforation. Sch. J. App. Med. Sci., 2015; 3(3G):15091515.

13. Sharma N, Sharma P, Sharma P, GouravK, Goyal VP.Comparison of ontological and audiological outcome of type I tympanoplasty using composite tragal perichondrium and temporalis fascia as graft. IntJ OtorhinolaryngolHeadNeck Surg.2018;4(5):xxx. DOI: http:/dx.doi.org10.18203issn2454-5929.ijohns 201834

14. Al Lackany M, Sarkis NN. Functional results after Myringoplasty and type-I Tympanoplasty with the use of different Graft Materials. J Med Res Inst. 2005;26(4): 369-74. 


\section{Original Research Article}

15. Sprem N, Branica S, Dawidowsky K. Tympanoplasty after war blast lesions of the eardrum: retrospective study. Croat Med J. 2001;42(6):642-5.

16. Gupta P, Prajapati BJ, Gupta More Y, Mehta R, Sinha V. Different types of graft materials in Type-I Tympanoplasty. Ind J Otol. 2007 ;13:9-11.

17. Patil K, Baisakhiya N, Deshmukh PT. Evaluation of different graft material in type 1 tympanoplasty. Indian J Otol. 20141; 20 (3):106. DOI: 10.4103/0971-7749. 136844

18. Dabholkar JP, Vora K, Sikdar A. Comparative study of underlay tympanoplasty with temporalis fascia and tragal perichondrium. Indian J Otolaryngol Head Neck Surg. 2007;59(2):116-9. DOI: 10.1007/s12070-0070035-0. Epub 2007 Sep 14.

19. Jain A, Samdani S, Sharma MP, Meena V. Island cartilage vs temporalis fascia in type 1 tympanoplasty: A prospective study. Acta Otorrinolaringologica (English Edition). 2018;69(6):311-7.DOI: 10.1016/j. otorri. 2017.10.004.
20. Tang Herman MK. The perforated ear-drum: To repair or not. Hong Kong J Online. 1989;11:124-5.

21. Mathai J. Myringoplasty with temporalis fascia : Analysis of 200 cases. Indian J Otolaryngol Head Neck Surg. 1999;51(2):9-13. DOI: 10.1007/BF02997983.

22. SoodAS ,Pal P,Singla A. Comparative study of type 1 tympanlasty using temporalis fascia and tarsal cartilage with perichondrium as graft material. Int $\mathbf{J}$ Otorhinolaryngol Head Neck Surg. 2018;4(3):789-793. DOI: 10.18203/issn.2454-5929.ijohns20181873

23. Tarik Sapci et al ,Comparision between tympanoplasties with cartilage- perichondrium composite graft and temporal fascia graft in terms of hearing levels and healing. KBB:J Ear, Nose, Thro. 2006; 16(6):255-260.

24.Kalcioglu MT, Tan M, Croo A. Comparison between cartilage and fascia grafts in type 1 tympanoplasty. BENT. 2013;9(3):235-9.

\section{How to cite this article?}

Vijayasundaram S, Satyaprabhakara Rao Y, Deepthi Y. Efficacy of composite perichondrial-chondral graft in type 1 tympanoplasty a comparative study. Trop J Ophthalmol Otolaryngol.2019;4(3):219-226.doi:10.17511/jooo.2019.103.07 